Walter Ott

ottw@vt.edu

Comments welcome

\title{
Malebranche and the Riddle of Sensation
}

Forthcoming, Philosophy and Phenomenological Research

Please see http://onlinelibrary.wiley.com/doi/10.1111/j.1933-1592.2012.00621.x/abstract

for offical version)

Like their contemporary counterparts, early modern philosophers find themselves in a predicament. On one hand, there are strong reasons to deny that sensations ${ }^{1}$ are representations. $^{2}$ For there seems to be nothing in the external world for them to represent. If one takes representation to require resemblance, the pressure in this direction is even stronger. On the other hand, some sensations - particularly color sensations - seem to be required for us to have perceptual experiences of bodies. How else could one perceive, or perhaps even think about, the boundaries of a body, except in terms of different shadings of color? Sensations must, it seems, represent at least some features of the mind-independent world.

I shall argue that Nicolas Malebranche offers an extreme - and ultimately unworkable attempt to resolve this tension. Much about Malebranche's theory of perception is controversial. There is one point, however, on which most commentators converge: Malebranche defends an adverbial theory of sensation. ${ }^{3}$ On such a view, a sensation is not a mental object, but merely a way in which an act of sensing happens. Malebranche garners praise for anticipating developments of twentieth century philosophy of mind by pioneering a new way to locate sensations in a mechanical world. ${ }^{4}$

The adverbial reading of Malebranche is wrong, or so I shall argue. Once we arrive at a more accurate reading, we shall see that his position is much stranger than is currently thought. Nevertheless, Malebranche's view is similar to the adverbial theory in one respect, albeit it at a very high level of generality. His view thus inherits two of the main problems that afflict adverbial theories, namely, how to individuate the objects of perception and how to understand the phenomenological 'projection' of sensations on to bodies. Although Malebranche fails to solve these problems, his ingenious attempts to do so are instructive.

The paper falls into two parts. Part I is devoted to the ontology of sensation. In the first section, I set out the core of the adverbial theory; in the second, I sketch Malebranche's view before showing, in the third, that the two are incompatible. What emerges is a view that is quite

\footnotetext{
${ }^{1}$ By 'sensation' here I simply mean sensory experiences of secondary qualities, in the broadest sense. The term is disambiguated below.

${ }^{2}$ For my purposes in this paragraph, I am deliberately leaving 'representation' unanalyzed. Below, I follow Steven Nadler (1992) and Alison Simmons (2009) in distinguishing between representation and intentionality.

3 See, e.g., John Cottingham (2000), Nicholas Jolley (1990, 1994, and 2000), Steven Nadler (1992), and Tad Schmaltz (1996). Of these figures, Schmaltz is the most circumspect; he claims that "[t]here is considerable reason to attribute to Desgabets and Malebranche alike an adverbial account of sensation according to which we have, for instance, a sensation of green not by perceiving a green mental object but rather by perceiving greenly” (1996, 257, n.138). Lawrence Nolan (2012) also argues against the adverbial reading, albeit on very different grounds.

${ }^{4}$ See Jolley (2000).
} 
foreign to contemporary adverbial theories, both in content and motivation. Although hard to take seriously today, Malebranche's position is intelligible in its own intellectual context. For I shall argue (in section four) that he presents one way of resolving a tension in Descartes's substance/mode ontology as applied to mental states.

Part II turns to the role of sensations in perception. Are sensations intentional states, directed at the idea of extension, or are they mere 'blank effects'? In section five, I set out the three roles Malebranchean sensations must play, and explain how they are connected with the chief problems facing adverbial theories. I argue that, while Malebranche clearly recognizes that sensations must play these three roles, he has no way of explaining how they could possibly do so. The sixth section examines Malebranche's later view, with its doctrines of efficacious ideas and intelligible extension. In the end, none of Malebranche's maneuvers succeeds, either on its own, or on contemporary, terms.

\section{Part I}

The ontology of sensation

$\S 1$. What is an adverbial theory?

Veridical experience seems to have an act-object structure: when we perceive, there is some object that is perceived. Adverbial theories deny that the act-object structure necessarily characterizes experience. As a first pass, we might say that an adverbial theory treats sensations not as the objects of sensings but as aspects of the sensory act itself. A sensation is not a mental item but a way in which the act of sensing happens. ${ }^{5}$ An extreme version of the theory might treat all sensory experiences, whether of primary or secondary qualities, or of full-fledged objects, in this way. Thus when Bobo senses the table, there is no object he is sensing; rather, he is performing the act of sensing in a certain way. But this is much less plausible than the restricted version I shall discuss, according to which it is only experiences of secondary qualities that are given an adverbial analysis. ${ }^{6}$

It is not hard to see what makes 'going adverbial' attractive. ${ }^{7}$ Sensations seem neither to be merely relational, nor to be representational; that is, they seem to be qualia. ${ }^{8}$ It is notoriously hard to see how qualia can be made to fit in a material world. But if qualia are just ways in which

\footnotetext{
${ }^{5}$ For the origin of the adverbial theory in C. Ducasse’s objections to G.E. Moore’s sense data theory, see esp. Martin (1998).

${ }^{6}$ As far as I can tell, this obvious distinction is rarely made in the literature. The theory mainly receives attention as applied to qualia rather than experiences of primary qualities. (Whether this restriction is more than ad hoc is open to doubt.) In a footnote, Michael Tye writes that "to my knowledge, no adverbial theorist denies that in statements of the type 'Person $\mathrm{P}$ sees object $\mathrm{X}$ ' the instances of ' $\mathrm{x}$ ' are genuine referring expressions. The adverbial approach is offered for statements of the form ' $\mathrm{P}$ has a sensation of $\mathrm{x}$,' ' $\mathrm{P}$ hallucinates $\mathrm{x}$,' ' $\mathrm{P}$ seems to see $\mathrm{x}$,' that is, sensory statements which can be true even if there is no real appropriate $\mathrm{x}$ in the offing. This simple point is sometimes missed by critics of the adverbial theory" (1984, 196-7, n.3).

${ }^{7}$ A further attraction might be epistemic, rather than metaphysical. For there is a nice fit between direct realism and restricted adverbialism. But see Laurence BonJour (2004) for persuasive doubts about the epistemic virtues of direct realism.

${ }^{8}$ This conception of qualia is stipulative. While I think it captures the minimal characteristics of qualia, not all would agree.
} 
sensory events happen, then there is no need to reduce qualia to items in the brain. The search for a reductive account of qualia would be as absurd as the search for a reductive account of slowly. The adverbialist can acknowledge the phenomenal nature of experience and at the same time avoid reifying color properties, either as mental objects or as mind-independent features of the world.

For my part, I find the view elusive. I just don't know what it could mean to say that I sense an object brown-ly. I am hardly alone in this. ${ }^{9}$ A more concrete challenge for the adverbialist is to explain the appearance of externality: color sensations at least seem to be 'about' objects in the world. But if they are non-representational in virtue of being adverbial, this feature slips from our grasp. Color sensations seem to be reports on how things are in the world, not autobiographical event-descriptions.

This 'externality' problem is connected with the individuation or 'many-property' problem, first raised by Frank Jackson: ${ }^{10}$ the adverbial analysis is too crude to account for the pairings between sensory states and their apparent objects. Sensory experience typically presents us with objects that we distinguish partly on the basis of color. But on the adverbial analysis, it seems, these distinctions are in danger of vanishing into one long adverbial modifier of a single perceptual act. Suppose Bobo senses a brown table and a yellow chair. He can be said to be sensing-brownly-yellowly. But what allows us to pair brown with the table, and yellow with the chair, rather than vice-versa? Non-representational states do not seem to be of the right type to be paired with or projected on to objects, or object-experiences.

My point in drawing this abbreviated sketch is not just to attack the adverbial theory, or to claim that it cannot answer the externality and individuation problems. Many able philosophers have tried to solve them. ${ }^{11}$ My point is simply that these are problems any successful adverbial theory must address. Below, I argue below that Malebranche is not an adverbialist. Nevertheless, his view faces its own versions of the externality and individuation problems.

\section{§2. Malebranche on sensation}

We must begin with a statement of Malebranche's general theory. In its broadest outlines, the theory claims that we see bodies neither directly nor by means of representations in our minds; instead, we see them only through ideas in God's mind. God's ideas being purely intellectual, they can have no sensory element; sensations must then be placed in the mind of the perceiver. ${ }^{12}$ This very rough statement of the 'vision in God' doctrine needs to be refined in

\footnotetext{
${ }^{9}$ BonJour (2007) writes, "the problem with it is that we seem to have no real understanding of the nature of the states in question or of how exactly they account for the character of immediate experience. It is easy, with a little practice, to construct the adverbial modifiers. But it is doubtful that anyone has a very clear idea of the meaning of such an adverb, of what exactly it says about the character of the state itself — beyond saying merely and unhelpfully that it is such as to somehow account for the specific character of the experience in question.” Cp. Lycan (1987, 87 f.)

${ }^{10}$ See Jackson (1977, 64 f.).

${ }^{11}$ See Tye (1984, discussed below, note 51) and Kriegel (2011) for replies.

12 Nadler (1992) ingeniously argues that Malebranche's ideas are logical concepts, rather than the objects of sensory experience, and that Malebranche is therefore a direct realist. I do not have space to revisit this debate. The texts I
} 
important ways. (I should note at the outset that Malebranche's view undergoes important changes that I discuss in section five below.)

Malebranche opens the Search After Truth with a distinction:

We can...say that the soul's perceptions of ideas are of two kinds. The first, which are called pure perceptions, are, as it were, superficial to the soul: they do not make an impression on it and do not sensibly modify it. The second, which are called sensible, make a more or less vivid impression on it. Such are pleasure and pain, light and colors, tastes, odors, and so on. For it will be seen later on that sensations are nothing but modes of the mind [manieres d'être de l'esprit] , and it is for this reason that I call them modifications of the mind. (SAT I.i/LO 2) ${ }^{13}$

Note that Malebranche here is not making quite the distinction one might expect. The present distinction is between two ways of perceiving ideas: purely and sensibly. Pure perceptions here are the sort of non-imagistic, purely intellectual thoughts one might have while doing geometry. Sensible perceptions are still perceptions of ideas, though they involve secondary qualities and make a more 'vivid impression' on the mind. So the contrast is not between two aspects of perceptual cognition, but between two kinds of perceptions. Nevertheless, the distinction we are seeking is implicit here, for sensible perception includes not only the perception of the idea but the sensation itself. This comes out more clearly much later in the Search:

When we perceive something sensible, two things are found in our perception: sensation and pure idea. The sensation is a modification of our soul, and it is God who causes it in us... As for the idea found in conjunction with the sensation, it is in God, and we see it because it pleases God to reveal it to us. God joins the sensation to the idea when objects are present so that we may believe them to be present and that we may have all the feelings and passions we should have in relation to them. (SAT III.ii.6/LO 234)

At this stage, it is utterly obscure how this 'joining' happens. It seems to mean nothing more than that God does two things at once: causing a sensation and revealing an idea. But this won't do. It is not merely that the soul undergoes these two changes at the same time, in the way one might suddenly feel hungry while working on a proof in geometry. The idea and sensation seem to be joined in a much more robust sense. Before going any further, we must get straight on the ontology: is Malebranche an adverbialist?

$\S 3$. An adverbial theory?

adduce here seem to show that ideas must at least be capable of playing a sensory role, as the objects on to which sensations are projected. Unlike Nadler, I do not think that all such passages can be read away.

${ }^{13}$ In citing Malebranche, I use the following conventions: The Search after Truth (SAT), trans. Lennon and Olscamp (LO); Dialogues on Metaphysics and Religion (D), ed. Jolley, trans. Scott, (JS); Oeuvres Complètes de Malebranche (OC). All quotations from OC are in my translation, unless otherwise noted. 
Malebranche's motivations could hardly be more distant from those of his contemporary counterparts. ${ }^{14} \mathrm{He}$ is clearly not aiming for a naturalization of qualia or defending materialism of any stripe. But a difference in motivation is not necessarily a difference in position.

Contemporary adverbialists are united in thinking of a given color sensation, call it $\mathrm{C}$, as modifying an act. There is the act of sensing the table, and when this act is done C-ly, we get the appearance of a C-colored table. The crucial point here is that sensations are adverbial modifications of acts, not of substances. No adverbialist would want to say that sensations are adverbial modifications of the brain; this would be a category mistake, since adverbs modify verbs, not nouns. A possible dodge here would be to try to make 'existing' the relevant verb, so that Bobo's sensing $C$ involves Bobo's brain's existing-C-ly. But then why not just say that $\mathrm{C}$ is a way the table has of existing? To say that $\mathrm{x}$ exists C-ly seems to be nothing but a rather odd way of saying that $\mathrm{C}(\mathrm{x})$. Thus if we are unhappy with saying $\mathrm{C}(\mathrm{x})$ where $\mathrm{x}$ is the table, it is hard to see why casting the brain, or whatever it is that thinks, as $\mathrm{x}$ should be preferable. Thus I take one essential feature of any adverbialism worthy of the name to be the following: color sensations are ways that acts are performed.

But this is not Malebranche's view. ${ }^{15}$ Consider the famous (or infamous) rainbowcolored soul passage:

You even make a fool of yourself before certain Cartesians if you say that the soul actually becomes blue, red, or yellow, and that the soul is painted with colors of the rainbow when looking at it. There are many people who have doubts, and even more who do not believe, that when we smell carrion the soul becomes formally rotten, and that the taste of sugar or of pepper or salt, is something belonging to the soul. (E XI/LO 634) ${ }^{16}$

Jolley uses this passage to introduce the adverbial reading. ${ }^{17}$ But it is poor evidence for this reading precisely because it takes color sensations to be modifications of a substance, not an act. We can draw out the consequences of this point by asking just what a genuine adverbialist view would have to look like in the context of Malebranche's ontology and vision-in-God doctrine. An adverbialist Malebranche would have to claim that when I perceive the idea in God, that act of perception has two aspects: it is directed at the idea, and it is performed C-ly, where 'C' specifies a color. But this is not what Malebranche says. Instead, it is the mind - not the act that exists in a certain way. Contemporary adverbialists would reject this, even if we replace 'mind' with 'brain' rather than 'soul.' In short, it is not just 'certain Cartesians' who will think you a fool if you say that sensing blue just is the sensing thing's turning blue. ${ }^{18}$

\footnotetext{
${ }^{14}$ Jolley $(2000,40)$ offers an intriguing comparison of the motivations of Malebranche and contemporary adverbialists.

${ }^{15}$ Nolan (2012, 38 f.) also argues against the adverbial reading, albeit on very different grounds. For Nolan, the problem is that the adverbial reading conflicts with the theory of natural judgments. In such judgments, we see extension as red, and not merely 'redly' $(2012,43)$. See below, Part II, for further discussion of Nolan's view.

${ }^{16}$ As Schmaltz (1996, 257, n.136) shows, this view was in fact attributed to Malebranche by his critics, particularly Anselme of Paris, in 1678. Note that Malebranche does not disavow it here.

${ }^{17}$ Jolley $(2000,37)$.

${ }^{18}$ See Jolley $(2000,37)$ for a defense of Malebranche on this point.
} 
Matters are still more dire for the adverbialist reading. Recall that the contemporary adverbialist is motivated partly by a desire to rid the world of what are otherwise ontologically suspicious mental objects, viz., qualia. But Malebranche has not analyzed away blue-ness as a mere aspect of an act. Blue-ness has instead been transformed into a state of a substance. This is precisely what contemporary adverbialists seek to avoid. Malebranche evades the naïve realism that casts mind-independent objects as colored only by casting the mind itself as phenomenally colored.

To all this, defenders of the adverbial reading might shrug their shoulders. Yes, Malebranche departs from the adverbial theory on this score. Sensations are modes of the soul rather than aspects of sensory acts. And yet it remains the case that sensation does not exhibit an act-object structure. Like the adverbialist, Malebranche denies that there is an object that is sensed.

Before replying, we must clear up some terminological issues, if only by stipulation. I shall follow Alison Simmons - who in turn follows Steven Nadler - in giving a minimal content to 'intentionality': an object or act is intentional if and only if it is directed at something outside itself. It is unclear precisely what Simmons means by 'representation'; clearly it includes - but means more than - directedness. ${ }^{19}$ As a first stab, we might say that $\mathrm{x}$ is a representation if it is in virtue of $x$ 's intrinsic features that the mind thinks about what $\mathrm{x}$ represents.

To see the difference, note that no Malebranchean act is representational; there is nothing intrinsic to the act of pure perception, for example, that explains why it is a (pure) perception of a square, or even the idea of one. ${ }^{20}$ Representation is the exclusive province of ideas, which are (sometimes) the intentional objects of mental acts. If those intentional objects are themselves representations, the mind can think through them to the representanda.

Second, we must note that 'sensation,' like its French counterparts, exhibits the familiar 'ing/ed' ambiguity. Are we talking about sensings, or things sensed? To mark this, I shall use 'sensing' for the act, and sensation only for the thing sensed, reserving 'sense experience' to refer, in the most neutral possible way, to whatever is happening in a mind when it experiences a secondary quality. Now, to make the ing/ed distinction is not to say that it marks a real difference. On the adverbial theory, a thing sensed, if it is anything at all, is an aspect of the sensing.

I now wish to go further and argue that Malebranche does indeed treat sense experience on the act/object model. For Malebranche, 'ing/ed' marks a real difference. He does in fact treat sensations as intentional, in our sense: sensings are acts directed at an object. If sensing counts as thinking, then this is inevitable: to think is to think of something. ${ }^{21}$ Sensing is thinking and so must have an object. ${ }^{22}$

19 Simmons (2009, 106; 116). Steven Nadler (1992, 81 f.) also distinguishes between intentionality and representation. Nadler takes intentionality to obtain between a perceiving and an idea, while representation links the idea with its object. (Nadler, of course, takes 'perception' in this context to be intellectual, not sensory, which helps enable him to read Malebranche as a direct realist.) Note that Simmons criticizes Jolley and Pyle for not noticing the distinction, but does not mention Nadler in this context. See below, Part II, for further discussion of the distinction. ${ }^{20}$ Simmons $(2009,124)$ makes this point.

21 “As M. Arnauld says, to think of nothing is not to think at all, i.e., there is no thought that lacks its object” (OC 9: 945).

22 "[B]y the words thought, mode of thinking, or modification of the soul, I generally understand all those things that cannot be in the soul without the soul being aware of them through the inner sensation it has of itself - such as 
We can go beyond this bare appeal to the logic of Malebranche's view and adduce concrete textual evidence. As Malebranche puts it in one of his replies to Arnauld: "the modalities of the soul are only the immediate object of our sensations, and not objects of knowledge” (OC 6: 55). Similarly, in a December 1690 letter, Malebranche writes, "your soul is green, or has a modification of green that you see when you are in the middle of a meadow, your eyes open” (OC 19: 564). ${ }^{23}$ What we see, in the strict sense, when we see color are only modes of the mind. Such passages could easily be multiplied. ${ }^{24}$ Once we make the ing/ed distinction, Malebranche's view should be clear. Sensing is a kind of sentiment intérieur, by which the mind is aware of its own modes; what it is aware of are sensations, or modes of the mind. So the adverbial reading has two strikes against it: sensations are not ways in which sensings are performed but modes of the soul that senses. Moreover, sensory experience exhibits an act-object structure, with the mode of the soul always serving as the object.

We cannot leave matters there, for I think the adverbial reading has one very important thing right. As we have seen, to say that a state or act is directed at an object and hence intentional is not to say that it is representational. Even in pure perception, the act of the mind is intentional, and yet it is not representational. The work of representation is left for the object of thought to perform, if it can.

On my view, sensings are intentional without being representational. In this, they are perfectly symmetrical with pure perceptions. The difference is that the object of a sensing is not an idea endowed with representational powers but a tenebreuse modification of the soul. Acts of pure perceiving are 'representational' in a derivative sense, in virtue of the representational powers of their direct objects. But the objects of sensings have no such powers. Sensations really are blank effects, like the feeling of being tickled or being in pain, and are not themselves representational. It is in this respect that Malebranche agrees with the adverbialist.

To get at this key point, we need to consider the Cartesian background of Malebranche's theory. Doing so will help show why sensations cannot be representational. And it might generate some sympathy for Malebranche’s rainbow-colored, carrion-scented soul.

\section{$\S 4$. The Cartesian background}

There are pressures within Descartes's substance/mode ontology that make Malebranche's view all but inevitable. Consider what it means, for Descartes, to say that a determinate shape is a mode of extension. ${ }^{25}$ In the Principles, Descartes claims that all this amounts to is that "one and the same body, with its quantity unchanged, may be extended in

sensations, imaginings, pure intellections, or simply conceptions, as well as its passions and natural inclinations” (SAT III.ii.1/LO 218). An anonymous referee has suggested that, as Malebranche's career progresses, the thesis that sensing is thinking (and hence cannot lack an object) does less and less philosophical work. It is true that Malebranche tends to put less emphasis on the claim that sensing is thinking and more on the claim that the mind finds in itself only modalities 'full of darkness.' Whether they count as objects of thought or not, what matters for my view is that sensations are objects of acts of sensing.

${ }^{23}$ Trans. and quoted in Schmaltz $(1996,83)$.

${ }^{24}$ See, e.g., SAT I.xiii/LO 61.

${ }^{25}$ For further discussion, see Ott (2006). 
many different ways" (AT VIIIA 31/CSM I 215). ${ }^{26}$ To call extension a mode of body is not to say that extension must itself modify some underlying substratum. Rather, the point is only that no determinate extension is essential to the body. In another sense, we can call extension the essence of body: "Thought and extension can be regarded as constituting the natures of intelligent substance and corporeal substance; they must then be considered as nothing else but thinking substance itself and extended substance itself - that is, as mind and body" (AT VIIIA 30-1/CSM I 215; my emphasis). Similarly, there is no substratum underlying the essence of body. Instead, an extended substance just is extension itself, considered in a different way. As Descartes puts this point, there is only a conceptual distinction between a substance and its essence.

What does this mean for thoughts, taken as modes? Descartes is committed to treating modes of mind and body symmetrically. So just as the shape of this table is its manière d'existence, so Bobo's thought of the table is a way his mind has of existing. Where these mental modes are ideas, Descartes wishes to distinguish between their objective and formal reality. The mind does not become the table when it thinks of it; instead, it is modified by a mode, an idea, that has an objective reality, that is, that represents the table. So the mode/content distinction, however one wishes to make this out, allows Descartes to avoid saying that the mind is modified with the intentional objects of its representational modes.

If one denies that sensory modes have objective reality, there seems to be no way to stave off this counter-intuitive consequence. ${ }^{27}$ It is only in virtue of pointing to the representational status of mental modes that Descartes can resist saying that the mind is modified by the objects of its ideas. The symmetry of Descartes's analyses of modes of thought and extension requires us to say that just as the squareness of the table is a way the table exists, so the idea is a way the mind exists. Without an idea/content distinction, the putative content collapses back into the mode. If sensations are not êtres representatifs, there is no distinction between their status as modes and what they present, i.e., between their formal and objective reality. ${ }^{28}$ Equivalently, we might say that they lack objective reality. So what on a representational account of sensation could be safely sequestered in the content of the sensory idea now must characterize the mind that has that sensation, just as square characterizes a square body. ${ }^{29}$

\section{Part II}

The (non-)intentionality of sensations

\footnotetext{
${ }^{26}$ References to Descartes are to the Cottingham, Stoothoff, and Murdoch translation ('CSM') and to Adam and Tannery's edition of Descartes's work ('AT').

${ }^{27}$ It is far from obvious that Descartes's sensations are representations, that is, that they have objective reality. Laura Keating (1999) argues - decisively, in my view - that they are not. For further discussion, see Simmons (1999) and Raffaella De Rosa (2010).

${ }^{28}$ Here it is intriguing to compare Berkeley's remarks in A Treatise concerning the Principles of Human Knowledge Part I §49. Although I do not have space to argue for this here, I believe Berkeley's treatment of perception is designed precisely to avoid this Malebranchean consequence.

${ }^{29}$ It is tempting to object that a parallel argument could show that, for Malebranche, the soul in thinking of extension must itself be extended. But notice that in the case of the perception of ideas, it is only the act and not the object that exists 'in' the soul. By contrast, the objects of sensory acts just are modes of the soul itself.
} 
The burden of this part of the paper is to show that Malebranche must deny that sensations exhibit intentionality. Since I take representation to be a special case of intentionality or 'aboutness,' my claim includes the denial that sensations are representations. ${ }^{30}$ While I disagree with the adverbial interpretation, its defenders have one important thing right: Malebranchean sensations are not the right sort of thing to point to or be about anything at all. This is so even though sense experience, as I have argued, has an act-object structure. For we are now concerned with sensations - things sensed - rather than acts of sensing.

This aspect of the dominant view has recently come under attack, in sophisticated analyses by Lawrence Nolan and Alison Simmons. While I agree with these commentators that Malebranche desperately needs sensations to exhibit intentionality, I shall argue that Malebranche's ontology makes it impossible for him to meet this need. ${ }^{31}$ It is in the very nature of an idea that one can, by perceiving it, think 'through' it to what it represents; by contrast, there is no means by which one might think 'through' a mode to an idea. ${ }^{32}$

Before we begin, we might note a general challenge for the opposition. Malebranche typically focuses on color, as, quite naturally, do his interpreters. But Malebranche clearly means his theory to include other sense modalities as well, as this passage from the Christian Meditations brings out: "Matter itself is intelligible only by its idea, which is intelligible extension: it is visible and sensible only because, on the presence of bodies, God represents intelligible extension to the mind and makes it sensible by its different colors, or the other sensations which are only modifications of its [the soul's] being." (OC 10: 99, my emphasis.) If the soul can take on the colors of the rainbow, it can equally acquire (formally, and not merely eminently) the smell of carrion. This consequence makes any view that attributes intentionality to sensations significantly less plausible than might at first appear.

Note that this sort of worry would vanish if sensations had discernible relations or isomorphisms to regions of extension. But such modes are known "only by an interior sentiment, and [are such that] one cannot discover the relations they bear to one another," let alone to the

30 While I am - I think - following Simmons (2009) in taking representation to be a species of intentionality, nothing hinges on using these terms in this way. Again, I mean my discussion to be as neutral as possible among competing theories.

${ }^{31}$ Simmons's case is a bit perplexing. While she argues at length that sensations are in fact directed, just like pure perceptions, at the idea of extension, she seemingly endorses the adverbial reading. As she puts it, for Malebranche, sensations “are so many ways of perceiving extension: bluely, redly, stinkily, sweetly, painfully, etc.” (2009, 125). If this is her view, then she cannot consistently claim that sensations are intentional, since no one denies that the adverbial reading deprives them of intentionality. I am not sure whether Simmons actually means to endorse the adverbial reading or not.

32 Simmons (2009, 122-3) argues that 'sensations-2' (what I have been calling simply 'sensations,' i.e., the objects of sensings) are 'Janus-faced,' in that they can be considered as modes of the mind and at the same time as acts directed toward the idea of extension. Her argument seems to be the following: the mind, for Malebranche, has only two faculties: understanding (the faculty of "receiving various ideas, that is, of perceiving various things" (SAT I.i1/LO 2) and the will. Simmons concludes that "there is simply no room [in Malebranche's framework] for nonintentional sensations that are neither ways of perceiving nor ways of willing” (2009, 123). But this is a bit hasty. On the next page of SAT, Malebranche seems to retract his claim that the understanding only receives ideas. "[I]t is the understanding that perceives modifications of the soul, or that senses them” (SAT I.i.1/LO 3). This is exactly what my reading predicts: the modification of the soul is the object sensed. Now, Simmons is quite right that Malebranche cannot abide sensings (what she calls 'sensations-1') that lack an object. But this does not show that sensings are sensings of ideas. 
idea of extension (OC 9: 956-7). If we restrict ourselves to color sensations, we find that the problem also vanishes if colors themselves have extension. But as Aristes says in the Dialogues, "I deny, Theodore, that color is extended. We see it as extended, but our eyes deceive us" (D V/JS 75). Malebranche's challenge is to explain this 'seeing-as.' Ultimately, I shall argue that, Malebranche's own efforts to the contrary, sensations really are blank effects or 'mental bruises,' in Simmons's phrase. ${ }^{33}$

\section{$\S 5$. Three roles for sensations}

Malebranche's early view (represented by the first editions of SAT) claims that there is an idea in God corresponding to every individual body in the world. By contrast, on the later view there is only one such idea in God's mind - what Malebranche calls 'intelligible extension' - with which we are in cognitive contact. There is a second difference: the doctrine of efficacious ideas. In the later period, Malebranche insists that, although God is the only true cause, ideas nevertheless can be said to act on minds. There is thus some sense in which the idea of intelligible extension causes my sensations. Arnauld accuses Malebranche of changing his mind, and many commentators follow suit. Ferdinand Alquié, for example, argues that Malebranche has replaced the vision in God with the vision by God. ${ }^{34}$ These two doctrines intelligible extension (henceforth 'IE') and efficacious ideas ('EI') - make for a fairly radical change in Malebranche's position, despite his protestations to the contrary. ${ }^{35}$ I propose to focus on the early view, as it is the more philosophically interesting. In this section, I present several problems for it. The following section briefly canvases the later view, arguing that it makes no progress in solving any of these problems.

Let us begin by setting out the work Malebranche needs sensations to do, marking the close analogies with the problems faced by the adverbial theory. First, sensations are required to make idea(s) sensible. Without a sensation, our experience of external objects would be incapable of making the kind of vivid impression on the soul it should, if we are to pay attention to those features of our environment that are relevant to our survival (SAT I.i/LO 2). Making an idea sensible requires solving the externality problem. Why should a color sensation, for example, direct our attention to an idea (and ultimately, through it, to a body), when that sensation is nothing but a mode of one's own mind? Malebranche's ontology makes matters worse. Since a mode is nothing but a way a substance has of being, "we cannot conceive a mode of a being unless at the same time we conceive the being of which it is a mode" (SAT III.ii.8/LO 244; see E X/LO 624). It would seem that in thinking of one's own sensations, one is actually thinking of oneself. This higher-order thought is always directed at the soul itself. But what of the first-order experience of colors? As merely 'blank effects,' they seem to direct one's thoughts nowhere at all.

\footnotetext{
${ }^{33}$ Simmons $(2009,107)$. For an illuminating discussion of the 'blank effects' view I am defending, see esp. Nadler (1992, 26 f.)

${ }^{34}$ See Alquié (1974, 209 f.) As Alquié notes, Malebranche goes right on talking as if there were particular ideas of bodies in God's mind, even after he introduces the notion of intelligible extension.

${ }^{35}$ Giving a precise date to these developments is difficult. The first edition of SAT is 1674; the Elucidations, 1678. Certainly by the time we reach Elucidation X, IE is in place. EI is rather harder to pin down; see Nolan (2012, 27, n.26) for more.
} 
Second, sensations make ideas particular. My experience of a square could not be an experience of this square in front of me without a sensation. The corresponding idea in God's mind is inherently general in the sense that it represents any square of the same dimensions. By contrast, modifications of minds are always particular. Thus if I am to use the idea to perceive an extra-mental object as a particular, I must somehow be adding a sensation to that idea.

It is important to distinguish this particularizing role from its closely related counterpart: individuation. ${ }^{36}$ The sensation must not only make the idea of the square an idea of this square; it must also mark off the idea of the square from those of the other shapes with which it might be surrounded. In the Réponse to Arnauld, Malebranche says, "the difference of ideas of visible bodies comes only from the difference of colors" (OC 6: 61). ${ }^{37}$ He illustrates this with an example: "For when on white paper I see a black body, this [sensation] determines me to see the black body as a particular body, which, without this color difference, would appear to me to be the same [as the paper]" (OC 6: 61). The parallel with Jackson's many-property problem should be clear. Both Malebranche and the adverbialist require some mechanism for pairing colors with objects: why is it that a given mode of the mind 'goes with' the cube in front of me, rather than with the sphere?

Malebranche recognizes that sensations must play all three of these roles (making sensible, particularizing, and individuating ideas). To do so, they must be 'joined' to the ideas in some robust sense. Mere co-occurrence - which might obtain between any two mental states, such as a headache and a thought of the Pythagorean theorem - is too weak to account for the phenomenology.

In this early period, we find Malebranche talking of the soul's projecting colors on to an idea via a natural judgment. When I look at a candle that is some distance away from me, the soul judges its color to be in the object itself. This judgment is, of course, false; and yet, where these "natural judgments of the senses" are concerned, the soul "is content to spread itself onto the objects it considers by clothing them with what it has stripped from itself” (SAT I.xii/LO 58). Our question, then, is whether projection via natural judgment can explain how sensations play these three roles.

My answer, of course, is 'no.' To make this case, we must look more closely at the theory of natural judgments. Judgment is the mechanism by which we paint extension with the mind's colors. These judgments are 'natural' in the sense that they are unavoidable in perceptual contexts. As Malebranche puts it, "[i]t should not be imagined that it is up to us to assign the sensation of whiteness to snow or to see it as white, or to assign the pain to the pricked finger rather than the thorn that pricks it. All of this occurs in us independently of us and even in spite of us as the natural judgments I spoke of...” (SAT I.xi/LO 55; see SAT I.vii).

It is the mind's job to 'see' objects in God as white, or as smelly. And yet these false though useful - judgments are not under the direction of the will, nor need they be transparently present to the mind making them. Malebranche, it seems, gives an almost Kantian answer to the externality problem: sensations seem to characterize objects outside of us only because we judge

\footnotetext{
${ }^{36}$ I owe this point to an anonymous referee.

${ }^{37}$ This is a later work (1684) and hence is committed to the denial of particular ideas of bodies (by IE). But IE need not be in tension with our quotation: there are, Malebranche might claim, no real differences among visible ideas, since there is just one of these, viz., intelligible extension. But insofar as there seem to be such differences, its only explanation is the essential difference among color sensations.
} 
that they do. This reading is open to decisive philosophical objections: in particular, it invites the charge of circularity. If we must judge (albeit sub-consciously) that this table is white, we first must have individuated in thought the table from its surroundings. And yet the only way to do this, Malebranche says again and again, is by means of color. But I cannot use my color sensations to individuate bodies if this process presupposes that those bodies are already individuated.

We must, then, back up and try again. Natural judgments are not Cartesian judgments that admit of a truth value and have propositional contents. Instead, they are simply compound sensations. The confusion is a natural one, since Malebranche is clearly treading the path first laid out in Descartes's Principles. There, Descartes insists that there are two ways of making judgments about sensations. One, which is quite correct, is that there is some cause in the object that brings about the sensation. The other, however, is always false, namely, that there is something resembling the sensation in the object. When we 'rapportons' or 'refer' sensations to objects in this second way, we are making a propositional claim, but one that is always false. ${ }^{38}$

By contrast, Malebranche is merely acquiescing in this way of talking when he calls some sensations 'judgments. ${ }^{39}$ In itself, a sensation is only a modification of the mind; but "considered in relation to the Author of Nature, who excites it in us," it can be considered a judgment (SAT I.vii/LO 34). ${ }^{40}$ An isolated sensation is merely a passion; when combined with others, it can be called a judgment because it presents objects as having color, or as existing at a certain distance from us. When the soul thinks of the fire as hot - what Descartes would have called 'referring' the heat to the fire - it is not making an unconscious judgment but undergoing a combination of sensations (SAT I.x/LO 52). Where Descartes saw a need for the mind to actively combine its sensations and ideas in a judgment, Malebranche sees only a need for God to cause sensations in us.

Nolan suggests that this passive role for the mind is the key to understanding Malebranche's view. Nolan recognizes that a natural judgment is merely a compound sensation. But neither, he claims, is it a mere mode of the mind, devoid of intentionality, in the sense we have specified. Instead, a natural judgment is a case of 'seeing-as.' In perception, the soul is modified by sensations and in this way is led to see the idea in God's mind as red or smelly or what have you. To the circularity objection, Nolan's notion of 'seeing-as' can offer a reply. An object is presented to the mind in sensation as already individuated and colored. It is not as if I am first presented with an unindividuated object and then must project color on to it in order to make it particular. As Malebranche says, "it is not up to us to assign the sensation of whiteness to snow or to see it as white” (SAT I.xi/LO 55).

Thus the externality problem disappears. Compound sensations come fully-formed as of objects with colors and dimensions. Now, Malebranche offers two explanations for our tendency to make free judgments about the externality of colors: the fact that objects 'act' on us through

\footnotetext{
${ }^{38}$ Principles I.70 (CSM I 218/AT VIIIA 34-5).

39 "The soul does not perform all the judgments that I attribute to it - these natural judgments are only sensations and I speak of them as such only for the sake of brevity and common speech" (SAT I.ix/LO 41). Similarly, Malebranche writes, "[a]s it is given to the senses only to sense and never, properly speaking, to judge, it is clear that this natural judgment is but a compound sensation...” (SAT I.vii/LO 34)

${ }^{40} \mathrm{I}$ am not claiming to explicate, or even to understand, this hieratic pronouncement. My present point is only that, taken in themselves, natural judgments are sensations.
} 
the motion of invisible particles to produce color sensations (SAT I.xi/LO 55), and the fact that color sensations are 'weak' as compared to sensations of pain (SAT I.xii/LO 58). But neither of these forces plays a role in our natural judgments: these are inflicted on us by God.

As a reading of Malebranche, Nolan's interpretation strikes me as exactly right. It produces a significant gain in clarity. But to my mind it re-locates, rather than solves, the problem. For if natural judgments are not a matter of Cartesian rapporter, where the mind takes an active role in projecting sensations on to objects, we are left with no real way to understand them. The notion of seeing-as seems designed to navigate a middle course between a full-fledged judgment and mere co-occurrence of sensations. For my part, I think this middle course is illusory: seeing-as must collapse into one or the other. 'Seeing $\mathrm{x}$ as $\mathrm{F}$ ' is just a paraphrase of the more perspicuous 'seeing that $\mathrm{x}$ is (or appears to be) F,' in which case it is a Cartesian judgment, after all. If so, then the circularity problem remains. Whether the judgment is voluntary or not is neither here nor there. ${ }^{41}$

Even if we leave this point aside, a further question obtrudes itself. Why is it that a sensation on its own is not a seeing-as, but when compounded with others, it becomes one? A natural answer is that a sensation of white takes up a certain region of visual space, and defines a region of extension, only when it is combined with the sensations of other colors that limit its extension. ${ }^{42}$ But Malebranche is not entitled to say this, since colors do not define regions of extension except insofar as they are paired with the idea of extension. And it is precisely this pairing we are trying to understand.

Let us take stock and see whether sensations can play any of the three roles Malebranche requires. First, color sensations cannot explain a key element of the 'sensibility' of ideas, namely, the fact that they present ideas (or the objects ideas represent) as 'outside' us. Nor can sensations particularize ideas. True, as modes of a mind, sensations are always particular. In some highly metaphorical sense, perhaps we can understand how joining a particular to an inherently general idea could make that idea represent another particular (though I have no idea how). Even granting all that, it would remain obscure how the particular mode is joined to the idea.

Nor is the individuation problem solved. Recall that Malebranche happily bites the bullet and claims that when the soul perceives color $\mathrm{C}$, it exists C-ly. If he is willing to tough out the

\footnotetext{
${ }^{41}$ At times, Nolan emphasizes the non-voluntariness of natural judgments as the "crucial difference" that marks them off from 'real' judgments (2012, 40). At others, he insists that natural judgments are only judgments by courtesy, and not merely because they are non-voluntary: unlike 'real' judgments, natural judgments are sensations. Nolan's view is consistent, of course; what he calls the 'crucial difference' need not be the only one. The sleight of hand comes when Nolan wants to claim that natural and real judgments "have the same content" (2012, 40). This makes sense if the only difference between natural and real judgments is whether or not they are voluntary. It does not make sense if the difference is that only real judgments have a propositional structure.

${ }^{42}$ Another possible move here would be to appeal Malebranche's seeming conflation of judgments with perceptions. As Malebranche puts it, "there is no difference on the part of the understanding between a simple perception, a judgment, and an inference, other than that the understanding by a simple perception perceives a simple thing without any relation to anything else whatsoever, that in judgments it perceives the relations between two or more things, and that in inferences it perceives the relations among the relations of things. Consequently, all the operations of the understanding are nothing but pure perceptions" (SAT I.ii/LO 7). By analogy, one might argue that in a compound sensation, one also is aware of the relations among the constituent sensations; this seems to be Nolan's view. But as we have seen, Malebranche denies this (OC 9: 956-7). Note that even Nolan is anxious to preserve the difference between natural and 'real' judgments (2012, 42-3).
} 
counter-intuitive consequences of such a view and really means to say that the soul exists blackly when it senses black, he is left with no resources to individuate ideas by means of color. To do this, he needs the soul to experience at least two colors simultaneously, so that one color can form the boundary of another. At the risk of seeming silly, we would then have to ask, can a soul be black all over and white all over at the same time? If instead it is somehow ideal 'regions' of the soul that turn black, how are these to be mapped on to the idea?

In Malebranche's example above, I see at one and the same time a black body (say, a pen) on a white piece of paper. White and black are modes of the mind. Now, even if we can appeal to 'seeing-as' and natural judgment to explain why these sensations seem to be outside of us, we must also figure out why it is that the idea of the pen appears black, and that of the paper, white. What makes it the case that the paper is seen as white? Nothing about its idea, since the idea is not, of course, itself white. Malebranche's early view, even when we take account of natural judgments, cannot answer this question.

To sum up: projection via natural judgment does nothing to explain how sensations can play the three roles Malebranche assigns to them. If Malebranche simply stipulates that in natural judgments we are presented with already individuated, sensible, and particular ideas, then he has named a problem, not solved it.

\section{$\S 6$. The later view}

At first glance, Malebranche's changes make things worse, not better. He rejects the claim that there is a one-one correspondence between individual bodies and ideas in God's mind; instead, there is only one such idea, namely, intelligible extension. We should begin by noting his motivation for introducing IE:

[W]hen I said that we see different bodies through the knowledge we have of God's perfections that represent them, I did not exactly mean that there are in God certain particular ideas that represent each body individually, and that we see such an idea when we see the body; for we certainly could not see this body as sometimes great, sometimes small, sometimes round, sometimes square, if we saw it through a particular idea that would always be the same. (E X/LO 627-8; cp. Radner 1978, 86)

Distance changes the apparent size of objects, and this apparent size can only be corrected through further natural judgments. ${ }^{43}$ It remains the case that one and the same material object seems now large, now small, depending on the perceiver's distance and perspective. But if the immediate object of thought is only an idea, how can it undergo these changes and yet remain the same? Ideas are, after all, supposed to be eternal and immutable. Further, whatever the persistence conditions for ideas of bodies might be, they surely include such features as size and shape. If these change, it is not clear how Malebranche could claim that I am perceiving the same idea over time. For these reasons, Malebranche now rejects his earlier claim (or, as he would

\footnotetext{
${ }^{43}$ How this happens, given Malebranche's analysis of natural judgments, remains a mystery to me.
} 
have it, his earlier façon de parler). Instead of a duplication of objects in a panoply of divine ideas, there is now said to be only one such idea.

Malebranche now needs color to particularize ideas in an altogether new sense. It is not just that an idea of a square is inherently general; there is now no idea of a square, only an utterly homogeneous idea of extension. Color must as it were 'light up' a region of intelligible extension to give it a square shape. A clear statement of this new role comes from the 1688 Dialogues on Metaphysics, where Malebranche has Theodore say:

[W]hen you sense or see [the circle], a determinate part of this [intelligible] extension sensibly touches your soul and modifies it by the sensation of some color. For intelligible extension becomes visible and represents a certain body in particular only by means of color, because it is only by the variety of colors that we judge the difference between the objects we see. All the intelligible parts of intelligible extension are of the same nature insofar as they are ideas, just as all the parts of local or material extension have the same nature as a substance. But as the sensations of color are essentially different, by means of them we judge the variety of bodies. (D I/JS 17; cp. Third Letter to Arnauld, OC 9: 959)

The second development - the doctrine of efficacious ideas - might hold out some promise for solving the problems I have raised. This is Nolan's, as well as Tad Schmaltz's, position. ${ }^{44}$ Note that, on EI, all talk of projection drops out. Instead, we can be said to 'sense' the idea of extension when it modifies our minds. Indeed, the 1688 Dialogues contain only one mention of natural judgments. ${ }^{45}$ Once we see, with Nolan, that natural judgments are just compound sensations, there is no special problem in combining them with the doctrine of EI. But have we made any gains in understanding how the overall view is supposed to work?

Combining IE with EI, we can say, with Nolan, that intelligible extension causes us to think of it in different ways "depending on how it affects the soul." 46 We see a region of intelligible extension as extended, under certain defined limits. Nolan acknowledges that we could not do this without sensations. On his view, as on Simmons's, sensations are intentional in the sense that they are directed at regions of intelligible extension.

If anything, IE makes the problems we've been discussing more pressing. To see this, let us turn back to Malebranche's example of a black body resting on a piece of white paper. The individuation problem asks, in virtue of what does (the idea of) the pen appear black, and (the idea of) the paper, white? There is nothing intrinsic to the idea(s) that can explain this, because

\footnotetext{
${ }^{44}$ Schmaltz recognizes that it is unclear "what it could mean to say that an idea 'becomes sensible' by means of sensation," or that the soul 'attaches' colors to an idea. Schmaltz argues that it is only when Malebranche has EI in place that he is in a position to cash out these metaphors (Schmaltz (2000, 76 f.). Nolan (2012, $31 \mathrm{f}$.) puts similar weight on EI. As Susan Peppers-Bates (2005) has argued, however, EI is in tension with Malebranche's official view that God alone is a true cause. EI can at best be a misleading way of speaking. Although I find Peppers-Bates's case convincing, I shall table the issue here, in order to give the fairest possible hearing to those views that depend on EI.

${ }^{45}$ It is interesting to note here that Malebranche speaks in a very Cartesian way, almost paraphrasing Principles I.70. Malebranche writes, "by a kind of natural judgment, which is not free, we always refer sensations to what most suits the good of the body....as for color, we refer it to objects alone” (D XII/JS 219).

${ }^{46}$ Nolan $(2012,41)$.
} 
as we've noted there are no real regions in intelligible extension, and even if there were, they would be entirely uniform. How can a merely ideal region of intelligible extension act on my soul? If it acts at all, it must do so as undifferentiated, utterly uniform extension.

Nor is there any help to be had from EI. Merely being caused by intelligible extension is insufficient to imbue sensation with directedness, with intentional content. ${ }^{47}$ In pure perception, the mind's act of thinking of a square is directed at (again, a purely ideal 'region' of) intelligible extension. But in sensation, this is not the case; the soul sees only itself. What causal relations obtain is beside the point, or so I shall now argue. ${ }^{48}$

To make his case for the intentional powers of sensations, Nolan appeals to passages like the following:

When the idea of extension affects or modifies the soul with a pure perception, then the soul conceives simply this extension. But when the idea of extension touches the soul more vividly, and affects it with a sensible perception, then the soul sees or feels extension. The soul feels it or perceives it still more vividly when the perception with which intelligible extension modifies it is a pain. For color, pain, and all the other sensations are only sensible perceptions, produced in intelligences by intelligible ideas. (Christian Conversations, OC 4: 75-76, trans. Nolan 2012, 42)

While this establishes beyond doubt that intelligible extension causes sensations, it does nothing to show that sensations are directed at intelligible extension. Malebranche's placing color, pain, smell, and sound all on one level makes it hard to see how sensations could have extension as their intentional object. What sensations contribute, Malebranche is telling us, is vividness. They wake the soul up, as it were. The distinction Malebranche draws above is just the same one we began with in section two, namely, the distinction between pure perception and 'sensible' perception. But again, a sensible perception is not a perception through sensation of an idea. It is a pure perception that is accompanied by sensation.

My point here is simply this: that state $S$ is caused by $\mathrm{x}$ does not establish that $\mathrm{S}$ is directed towards or is about $x .{ }^{49}$ This is true even when $\mathrm{S}$ is a mental state. Let us leave aside Malebranche's metaphysics for a moment to make this general point. A state of sadness might be caused by hearing a certain song, but it would be odd to say that that state is therefore directed to

\footnotetext{
47 There is a further possibility here, one not explored in the literature. It might be the case that efficacious ideas allow us to give a causal story of the relation between sensations and states of objects. This would have to be rather convoluted, since of course material objects do not cause anything. Taking the appropriate loops through the divine will and the laws of nature, we might try to make out that sensations track mind-independent states of extension. But this will not do, since a) it makes sensations representations all over again, and b) as Schmaltz has shown, Malebranche denies that there is any tight correlation between sensory states and states of extension (see Schmaltz 1995, $387 \mathrm{f.}$ )

${ }^{48}$ By contrast, Jolley $(1994,216)$ claims that acting on the mind is both necessary and sufficient for a thing to be the mind's immediate object.

${ }^{49}$ Nolan writes, "intelligible extension can cause us to cognize it in different ways depending on how it affects the soul. So intelligible extension is the immediate object of all our perceptions, sensory or otherwise” (2012, 41). But this inference doesn't follow. That x causes state S doesn't by itself show that $\mathrm{S}$ is about or directed toward $\mathrm{x}$.
} 
or about the song. ${ }^{50}$ The mere fact that intelligible extension causes us to have sensations does nothing to supply those sensations with intentionality. To suppose otherwise is to strawman the defenders of the blank effect reading: they would have to deny that sensations are caused. But this is absurd; they deny only that sensations are themselves intentional or representational states. Finally, recall that intelligible extension also causes in us sensations of tickling and of odors. I would guess that even the commentators I am addressing want to deny that these are about or directed toward intelligible extension.

Thus, for all their differences, Schmaltz, Jolley, Simmons, and Nolan all place too much weight on the merely causal connection between idea and sensation. With Malebranche's later view, we trade one mystery - the soul's projecting color on to an idea so as to see it as F - for another - the mechanism by which the idea of intelligible extension causes us to see it as F.

\section{$\S 7$. Conclusion}

Malebranche stakes out a particularly stark position. Sensations are not representations, nor do they exhibit intentionality; they are nothing but modifications of a mind. We have seen that this position cannot be rehabilitated by lumping it in with contemporary adverbial theories. Nor can Malebranche's ingenious strategies - natural judgments, intelligible extension, efficacious ideas, or any combination of these - help him imbue sensations with objectdirectedness. What is sensed is always and only a mode of the mind and not extension, intelligible or otherwise.

The exasperated reader might ask, what is the philosophical upshot of all of this? What do we learn by fighting our way through the thicket of possible readings of Malebranche in an effort to solve the externality and individuation problems? If there is any lesson here, it is an inductive one: if Malebranche cannot solve these problems, it is doubtful that any view that treats sensations as blank effects can. The various strategies pursued by Malebranche and his commentators might not exhaust all possible solutions, but the onus is now on the defender of the blank effect view to offer a new one. ${ }^{51} 52$

\footnotetext{
${ }^{50}$ Consider that even a contemporary adverbialist might appeal to causation. Indeed, she would be better placed than Malebranche to do so, since on her view it is the physical object itself that causes our sensations. She then faces the objection that nothing about the sensation ties it to one object in the visual field rather than another. To appeal to causation is to beg the question. For the difference between a brown table and a yellow chair has to be drawn from the subject's perspective. The subject must have access to whatever it is that pairs brown or brownly with table, and yellow or yellowly with chair. That one sensation is caused by the table and the other by the chair is neither here nor there, for such a relation, standing outside the subject's sphere of awareness, can do nothing to pair sensation with object from the subject's point of view. In brief, if causation were sufficient, then the adverbial theory would never have faced the problem of individuation. But it does, so it's not.

${ }^{51}$ While I am certainly not familiar with each and every such attempt to solve the individuation problem, the most promising one seems to me to have been developed by Tye (1984). Tye introduces a novel function, 'coincidence' or 'Coin,' that maps “any two given sensory modes or functions $F$-ly and $G$-ly onto a function which, in turn, maps the property of sensing onto a further sensing property which is usually instantiated in normal perceivers by virtue of their viewing a physical object, which both $F$ and $G$, in standard circumstances” $(1984,218)$. To my mind, the Coin function is a sophisticated statement of the gap in adverbial theories located by the individuation problem. It does nothing, except by stipulation, to fill this gap.

${ }^{52}$ I am grateful to Larry Nolan and an anonymous referee for helpful comments.
} 


\section{References}

Alquié, Ferdinand. 1974. Le Cartésianisme de Malebranche. Paris: J. Vrin.

Arnauld, Antoine. 1990. On True and False Ideas. Trans. S. Gaukroger. Manchester, UK: Manchester University Press.

BonJour, Laurence. 2004. “In Search of Direct Realism.” Philosophy and Phenomenological Research 69, 2: 349-67.

----. 2007. “Epistemological Problems of Perception.” Stanford Encyclopedia of Philosophy.

Cottingham, John. 2000. "Intentionality or Phenomenology? Descartes and the Objects of Thought.” In T. Crane and S. Patterson, eds., History of the Mind-Body Problem. London: Routledge.

De Rosa, Raffaella. 2010. Descartes and the Puzzle of Sensory Representation. Oxford: Oxford University Press.

Descartes, René. 1904. Oeuvres de Descartes, ed. C. Adam and P. Tannery. 11 vols. Paris: J. Vrin.

----. 1984. The Philosophical Writings of Descartes, ed. John Cottingham, Robert Stoothoff, and Dugald Murdoch. 3 vols. New York: Cambridge University Press.

Jackson, Frank. 1977. Perception: A Representative Theory. Cambridge: Cambridge University Press.

Jolley, Nicholas. 1990. The Light of the Soul. Oxford: Clarendon Press.

----. 1994. “Intellect and Illumination in Malebranche.” Journal of the History of Philosophy 32: 209-23.

----. 1995. "Sensation, Intentionality, and Animal Consciousness: Malebranche's Theory of the Mind.” Ratio 8, 2: 128-142.

----. 2000. “Malebranche on the Soul.” In Nadler, ed., The Cambridge Companion to Malebranche.

Keating, Laura. 1999. 'Mechanism and the Representational Nature of Sensation in Descartes,' Canadian Journal of Philosophy 29, 3: 411-430.

Kriegel, Uriah. 2011. Sources of Intentionality. Oxford: Oxford University Press. 
Lycan, William G. 1987. Consciousness. Cambridge, MA: MIT Press.

Malebranche, Nicolas. 1958-67. Oeuvres Complètes de Malebranche. Dir. A. Robinet. 20 vols. Paris: J. Vrin.

----. 1997a. The Search After Truth. Trans. T. Lennon and P. Olscamp. Cambridge: Cambridge University Press.

----. 1997b. Dialogues on Metaphysics and on Religion. Trans D. Scott, ed. N. Jolley. Cambridge: Cambridge University Press.

Martin, M.G.F. 1998. “Setting Things Before the Mind,” in A. O’Hear, ed., Contemporary Issues in the Philosophy of Mind. Cambridge: Cambridge University Press.

Nadler, Steven. 1992. Malebranche and Ideas. New York: Oxford University Press.

----, ed. 2000. The Cambridge Companion to Malebranche. Cambridge: Cambridge University Press.

Nolan, Lawrence. 2012. "Malebranche on Sensory Cognition and 'Seeing As.'” Journal of the History of Philosophy 50, 1: 21-52.

Peppers-Bates, Susan. 2005. “Does Malebranche Need Efficacious Ideas?” Journal of the History of Philosophy 43, 1: 83-105.

Pyle, Andrew. 2003. Malebranche. London: Routledge.

Radner, Daisie. 1978. Malebranche. Amsterdam: Van Gorcum Assen.

Reid, Jasper. 2003. “Malebranche on Intelligible Extension.” British Journal for the History of Philosophy 11, 4: 581-608.

Rodis-Lewis, Geneviève. 1963. Nicolas Malebranche. Paris: Presses Universitaires de France.

Schmaltz, Tad. 1996. Malebranche's Theory of the Soul. Oxford: Oxford University Press.

----. 2000. "Malebranche on Ideas and the Vision in God.” In Nadler, ed., The Cambridge Companion to Malebranche.

Simmons, Alison. 1999. “Are Cartesian Sensations Representational?” Noûs 33: 347-369.

----. 2003. "Descartes on the Cognitive Structure of Sensory Experience.” Philosophy and Phenomenological Research 67, 3: 549-579. 
Tye, Michael. 1984. “The Adverbial Approach to Visual Experience.” The Philosophical Review 93, 2: 195-225.

Wilson, Margaret. 1990. "Descartes on the Representationalist of Sensation.” In M. Kulstad and J. Cover, eds. Central Themes in Early Modern Philosophy. Indianapolis: Hackett, $1-22$. 